\title{
非晶質カルコゲン化ヒ素の表面自由エネルギー
}

\author{
李潔・小笠原敏文*・服部 信 \\ $\left(\begin{array}{l}\text { 広島大学 工学部 } \\ * \text { マツダ }(\text { 株 }\end{array}\right)$
}

硫化ヒ素とセレン化ヒ素の非晶質粉体につき，水のほか数種の有機液体の接触角 $\theta$ を測定した。 表面自由エネルギ一（表面張力）を，分散力成分 $\gamma^{\mathrm{D}}$ 上極性成分 $\gamma^{\mathrm{P}}$ に分け，界面張力に幾何平均 近似を適用して，固体の表面張力を試算した。ただし， $\cos \theta$ と $\left(\gamma_{\mathrm{L}}^{\mathrm{D}}\right)^{1 / 2} \cdot \gamma_{\mathrm{L}}^{-1}$ は直線関係になるこ 亡 ( $\gamma_{\mathrm{L}}$ は液体の表面張力), $\cos \theta=1$ では $\gamma^{\mathrm{P}}$ が無視できること, $\theta>0^{\circ}$ のとき表面圧は無視でき

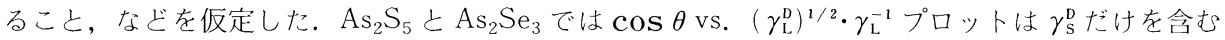
直線之なり（ $\gamma_{s}$ は固体の表面張力）, こう配から求めた $\gamma_{s}^{\mathrm{D}}$ はそれぞれ $34.4 \mathrm{~mJ} \cdot \mathrm{m}^{-2}$ と 37.5 $\mathrm{mJ} \cdot \mathrm{m}^{-2}$ である. $\mathrm{As}_{2} \mathrm{~S}_{3}$ の場合は分散成分と極性成分 $\gamma_{\mathrm{s}}^{\mathrm{P}}$ を含むこう配となり， $\gamma_{\mathrm{s}}^{\mathrm{D}}$ は $25 \mathrm{~mJ} \cdot \mathrm{m}^{-2}$ で ある. $\gamma_{\mathrm{s}}^{\mathrm{p}}$ は $1 \sim 8 \mathrm{~mJ} \cdot \mathrm{m}^{-2}$ の範囲となり, 分散力成分よりかなり小さいと推定される.この結果より, これらのカルコゲン化物は低表面エネルギーであると考えられる.

(1985 年2月 25 日受付)

\section{Surface Free Energies of Amorphous Arsenic Chalcogenides}

\author{
Jie LI, Toshibumi OGASAWARA* and Makoto HATTORI \\ Faculty of Engineering, Hiroshima University \\ Saijo-cho, Higashi-Hiroshima-shi 724 \\ * Mazda Motor Corporation
}

\begin{abstract}
Contact angle measurements have been carried out on powders of amorphous arsenic chalcogenides using water, formamide, ethylene glycol, 1, 3-butanediol and 1-nitropropane as wetting liquids. The dispersion and polar components of the surface free energy, $\gamma_{\mathrm{s}}^{\mathrm{D}}$ and $\gamma_{\mathrm{s}}^{\mathrm{p}}$, have been calculated from the geometric mean equation. Three approximations have been made in the present approach : (1) The relation between $\cos \theta$ and $\left(\gamma_{\mathrm{L}}^{\mathrm{D}}\right)^{1 / 2} \cdot \gamma_{\mathrm{L}}^{-1}$ is linear $\left(\gamma_{\mathrm{L}}\right.$ is the surface tension of the wetting liquid), (2) Near $\cos \theta=1$ the polar contribution is negligible as compared to the dispersion contribution, (3) The surface pressure is not taken into account for the case of $\theta>0^{\circ}$. The plots of $\cos \theta$ of $\mathrm{As}_{2} \mathrm{~S}_{5}$ and $\mathrm{As}_{2} \mathrm{Se}_{3}$ against $\left(\gamma_{\mathrm{L}}^{\mathrm{D}}\right)^{1 / 2} \cdot \gamma_{\mathrm{L}}^{-1}$ lie on the straight lines which can be obtained in the case where only the dispersive interaction is present. The $\gamma_{\mathrm{s}}^{\mathrm{p}} \mathrm{s}$ of $\mathrm{As}_{2} \mathrm{~S}_{5}$ and $\mathrm{As}_{2} \mathrm{Se}_{3}$ obtained from the slopes of the lines were 34.4 and $37.5 \mathrm{~mJ} \cdot \mathrm{m}^{-2}$, respectively. In the case of $\mathrm{As}_{2} \mathrm{~S}_{3}$ both dispersion and polar components are considered to be present. The estimated $\gamma_{\mathrm{s}}^{\mathrm{D}}$ was $25 \mathrm{~mJ} \cdot \mathrm{m}^{-2}$, while $\gamma_{\mathrm{s}}^{\mathrm{p}}$ varied from liquid to liquid and was in the range of about 1 to $8 \mathrm{~mJ} \cdot \mathrm{m}^{-2}$. The present results are compared with those of organic polymers of low surfce energies.

[Received February 25, 1985]
\end{abstract}

Key-words: As-Chalcogenide, Contact angle, Surface tension, Surface free energy

\section{1. 緒 言}

固体材料を機能的に活用しようとするとき，その表面 の性質を知ることは重要である。粉体の焼結現象はもち ろん，吸着や表面が介在する化学反応に，表面状態が深 い係わりをもつことはいうまでもない。酸化物表面は, セラミック材料や固体触媒の化学と関連して, これまで に広く研究対象とされてきた。しかし，近年新しいセラ ミック原料として注目されている炭化物や窒化物のよう
な非酸化物については，その表面性状に関する研究が極 めて少ない.

表面では原子や分子をかこむ状涊が，内部におけるも のと大きく異なるため, 表面あるいは界面は広義の構造 矢陥である。内部に比へて常に過剩なエネルギーをもち， 不安定であることが表面の活性の原网々なる。表面積に 比例して増減するこの過剩エネルギ一が，表面エネル ギーと呼ばれるものである、焼結や吸着の現象も，結果 
的には表面エネルギ一減少の方向への変化として, 熱力 学的な説明が与えられる. 表面工ネルギ一は, 単位面積 だけ表面を増加させるのに必要なエネルギーとして定義 できる，液体の場合は，分子の移動が容易なため，表面 積を増加しても直ちに平衡状態に到達するため, 表面工 ネルギー，あるいは表面張力の直接測定が容易である。 固体の場合，原理的には結晶をへき開するときのエネル ギーから，そのへき開面の表面エネルギーを直接求める ことができる，しかし，原子やイオンの移動が液体のよ うに容易ではなく、ひずみの残留等のためその值がよ゙れ だけ正しいかには問題が残る。

一方，間接的な方法として従来もっとも多く用いられ ているのは, 表面張力の分っている液体との接触角を測 定し, 固液界面張力に近似を適用して固体の表面張力を 算出するやり方である。極性が少なく低エネルギーの表 面，例えばポリエチレンやテフロンのようなものの表面 にこの方法を適用した例が多く, ある程度成功している. しかし, 表面エネルギーが液体の表面張力をはるかに上 回る固体では，接触角が 0 になってしまうので，この方 法は使えないことになる. セラミック材料を対象とした 報告が極めて少ない理由の一つである.

著者らは, 炭化物, 窒化物, 硫化物等の非酸化物無機 粉体の浸漬熱や接触角を測定し, 表面性状を界面熱力学 の立場から考察する一連の研究を行っている. 炭化物之 して $\mathrm{SiC}$, 窒化物として $\mathrm{Si}_{3} \mathrm{~N}_{4}$, 硫化物として硫化七素 を取り挙げ，成果の一部を公表した ${ }^{11 \sim 31}$. 本研究はその 一環として行ったものであり, 疎水性で低エネルギーの 表面をもつと思われる $\mathrm{As}_{2} \mathrm{~S}_{3}, \mathrm{As}_{2} \mathrm{~S}_{5}$ 及び $\mathrm{As}_{2} \mathrm{Se}_{3}$ を対 象とし, 水及び数種の有機液体の接触角を測定し, 表面 エネルギーの分散力成分と極性成分の算出に対する, 従 来の接触角法の適用性を検討したものである.

\section{2. 実 験}

\section{1 試料}

$\mathrm{As}_{2} \mathrm{~S}_{3}$ 及び $\mathrm{As}_{2} \mathrm{~S}_{5}$ は沈澱法によって調製した。 $\mathrm{As}_{2} \mathrm{Se}_{3}$ はシリカガラスアンプル中に As と $\mathrm{Se}$ の単体を 調合封入し, 搖動電気炉中で融解したのち室温まで急冷 して得たガラスを粉砕して用いた. $\mathrm{As}_{2} \mathrm{~S}_{3}$ 及び $\mathrm{As}_{2} \mathrm{~S}_{5}$ は，それぞれ $\mathrm{As}^{\mathbb{1}} \mathrm{O}_{3}^{3-}$ 及び $\mathrm{As}^{\mathrm{V}} \mathrm{O}_{4}^{3-}$ イオンを含む酸性溶 液に, $\mathrm{H}_{2} \mathrm{~S}$ を通じて沈殿させた. $\mathrm{As}_{2} \mathrm{~S}_{5}$ の調整に際し, 酸濃度が低すぎたり, $\mathrm{H}_{2} \mathrm{~S}$ を流すときの冷却が穏やか すぎると, しばしば $\mathrm{As}_{2} \mathrm{~S}_{3}$ と $\mathrm{S}$ に分解するので, この 点に特に注意した。

以上の 3 試料は，いずれも非晶質の粉末 X 線回折図 を与えた。調製操作は前報”に述べたとおりである。

接触角測定には水のほかにホルムアミド，エチレング リコール，1，3-ブタンジオール及び 1-ニトロプロパンを 用いた. 有機液体は市販特級試薬を脱水して用いた。水
はイオン交換水を 2 回蒸留したものを用いた。

\section{2 接触角測定}

接触角は平滑な固体表面に液滴を形成し, 拡大したプ ロフィル写真上で測るか，ゴニオメータ一付きの望遠鏡 で直接測定するのが普通である.しかし，著者は粉体と しての表面性状を調べることを目的としているので，粉 末法によって間接的に測定した。粉末法にも幾つかの方 法があるが，ここでは粉体を充てんしたカラム中を液体 が浸透する速度から求好方法を用いた。

下端に沃紙をはった内径の均一なガラス管に試料をつ め, 鉛直に支持して下端を液面に接触させる. 読み取り 顕微鏡を用いて, 浸透液前線の到達距離, $l$, を時間, $t$, の関数として測定する. $l^{2}$ を $t$ に対してプロットする 之, 原点を通る直線になる 立つ。

$$
l^{2}=\gamma_{\mathrm{L}} \cos \theta r t / 2 \eta
$$

ここで $\gamma_{\mathrm{L}}$ は液体の表面張力, $\theta$ は接触角, $r$ は粉体力 ラムに毛細管をたばねたモデルを適用したときの毛管の 半径, $\eta$ は液体の粘性係数である.表面を完全に妨す $(\theta$ =0）液体については，（1）式は

$$
l^{2}=\gamma_{\mathrm{L}}^{\prime} r t^{\prime} / 2 \eta^{\prime}
$$

となる， $\gamma_{\mathrm{L}}^{\prime}, t^{\prime}, \eta^{\prime}$ はすべて $\theta=0$ の液体についての数 値である。（1）式と（2）式から $r$ を消去すると

$$
\cos \theta=K \times\left(t^{\prime} / t\right) \text { ただし } K=\gamma_{\mathrm{L}}^{\prime} \eta / \gamma_{\mathrm{L}} \eta^{\prime} \quad(3)
$$

となる.したがって, $\theta=0$ の液体と $\theta$ が未知の液体に ついて浸透実験を行い, ある設定した $l$ まで到達するの に要した時間 $t^{\prime}$ 及び $t$ を測定すれば，（3）式によって $\theta$ を求めることができる.

本実験では, $2 \mathrm{ml}$ のメスピペット（内径約 $3 \mathrm{~mm}$ のも の) の中から, 内径の均一なものを選び（水の重量から 検定した), 試料粉体を充てんした，充てん密度ができ るだけ等しくなるようにして，1 種類の液体に付き 5 本 のカラムで測定して平均した。 $\theta=0$ の標準液にはトル エンや四塩化炭素がよく用いられる。本実験ではこの両 者を用いた結果が，非常に近い結果となったので，平均 したものを測定值とした。測定值のばらつきは10\%以

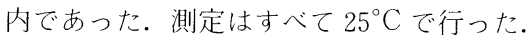

\section{3. 結果と考察}

\section{1 接触角}

接触角 $\theta$ の測定值を表 1 に示す. $\mathrm{As}_{2} \mathrm{~S}_{5}$ と $\mathrm{As}_{2} \mathrm{Se}_{3}$ の カラムでは，水の浸透上昇は起こらなかった。すすおち $\theta>90^{\circ}$ であることが分った.このような場合の便法上 して，水／アルコールの混合液の $\theta$ を測定し，水 $100 \%$ に外そうして求める方法が報告されている6!。こでも それにならって, メ夕ノール／水混合液の $\theta$ を測定し た. メ夕ノールのモル分率 $X_{\mathrm{m}}$ に対する $\cos \theta$ の依存性 は, 図 1 から分るようにメ夕ノ一ルの低濃度域でよい直 
Table 1. Observed contact angles

\begin{tabular}{|c|c|c|c|}
\hline \multirow[t]{2}{*}{ Liquid } & \multicolumn{3}{|c|}{ Contact angles $\theta /$ deg } \\
\hline & $\mathrm{As}_{2} \mathrm{~S}_{3}$ & $\mathrm{As}_{2} \mathrm{~S}_{5}$ & $\mathrm{As}_{2} \mathrm{Se}_{3}$ \\
\hline Water & 79 & 109 & 102 \\
\hline Formamide & 71 & 85 & 73 \\
\hline Ethylene glycol & 62 & 69 & 63 \\
\hline 1,3-Butanediol & 56 & 50 & 40 \\
\hline 1-Nitropropane & 39 & 38 & 30 \\
\hline
\end{tabular}

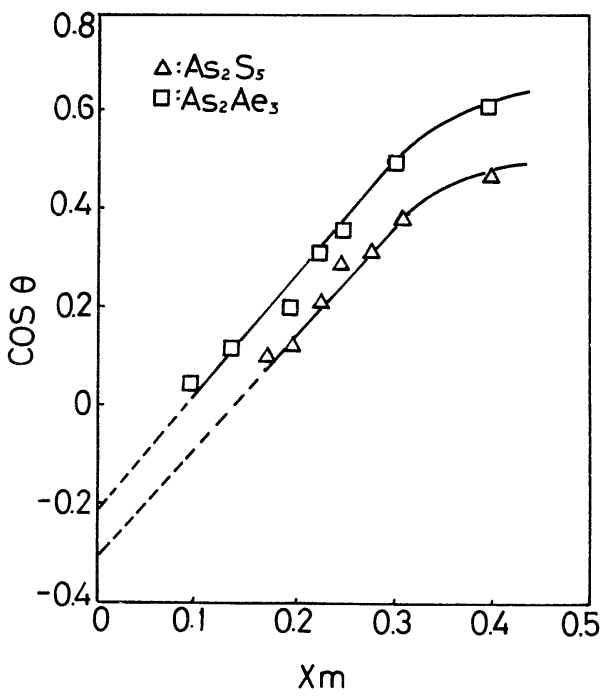

Fig. 1. $\operatorname{Cos} \theta$ of methanol-water solution on $\mathrm{As}_{2} \mathrm{~S}_{5}$ and $\mathrm{As}_{2} \mathrm{Se}_{3} . X_{\mathrm{m}}=$ mol fraction of methanol

線性を示したので $X_{\mathrm{m}}=0$ の外そう值を $\mathrm{As}_{2} \mathrm{Se}_{5}$ 及び $\mathrm{As}_{2} \mathrm{Se}_{3}$ と水の接触角とした.

\section{2 接触角と表面張力}

平滑な固体面に接触角 $\theta$ で安定な液滴が形成された とすると(図2)，つり合いの条件から

$$
\gamma_{\mathrm{sv}}=\gamma_{\mathrm{sL}}+\gamma_{\mathrm{L}} \cos \theta
$$

が成り立つ.ここで， $\gamma_{\mathrm{sv}}$ は固体／蒸気の界面張力で, $\gamma_{\mathrm{L}}$ は液体の表面張力である。固体面に蒸気が吸着する 之, 固体の表面張力 $\gamma_{\mathrm{s}}$ は $\pi_{\mathrm{e}}$ (表面圧) だけ低下する. すなわち

$$
\gamma_{\mathrm{sv}}=\gamma_{\mathrm{s}}-\pi_{\mathrm{e}}
$$

界面張力 $\gamma_{\mathrm{SL}}$ を直接測定することは困難なので, 界面 で接している 2 相の表面張力で表そうとする近似が幾つ か提出されている. そのうちでもっとも多く用いられて いるのは，幾何平均近似である，表面張力は，表面にあ る分子等が分子間等の凝集力で, 内部に引つ張られるこ

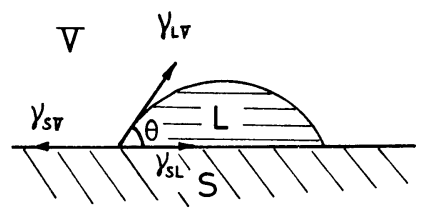

Fig. 2. Illustration of wetting $\left(\theta<90^{\circ}\right)$ liquid on a solid
とによって生ずると考えることができる．界面では相 1 の表面張力 $\gamma_{1}$ と相 2 の表面張力 $\gamma_{2}$ が働いているので, その合計が当然界面張力に寄与する. 一方, 相 1 の分子 と相 2 の分子の間には, 分散力そのほか引力が働いてい るので，その分を $\gamma_{1}$ と $\gamma_{2}$ から差し引かなければならな い.この引力相互作用に基づく奇与が $\left(\gamma_{1} \gamma_{2}\right)^{1 / 2}$ に等し い, 亡するのが幾何平均近似である゙。

すなわち，相 1 と 2 の界面張力 $\gamma_{12}$ 在

$$
\begin{aligned}
\gamma_{12} & =\gamma_{1}-\left(\gamma_{1} \gamma_{2}\right)^{1 / 2}+\gamma_{2}-\left(\gamma_{1} \gamma_{2}\right)^{1 / 2} \\
& =\gamma_{1}+\gamma_{2}-2\left(\gamma_{1} \gamma_{2}\right)^{1 / 2}
\end{aligned}
$$

亡する.この近似を用いると

$$
\gamma_{\mathrm{SL}}=\gamma_{\mathrm{S}}+\gamma_{\mathrm{L}}-2\left(\gamma_{\mathrm{S}} \gamma_{\mathrm{L}}\right)^{1 / 2}
$$

と書くことができる.（5）式（7) 式を(4) 式に代 入すると，

$$
\cos \theta=-1+2\left(\gamma_{\mathrm{S}} \gamma_{\mathrm{L}}\right)^{1 / 2} \cdot \gamma_{\mathrm{L}}^{-1}-\pi_{\mathrm{e}} \cdot \gamma_{\mathrm{L}}^{-1}
$$

となる. 表面張力は分散力に上る成分 $\gamma^{\mathrm{D}}$ と, 静電的相 互作用や水素結合等の極性成分 $\gamma^{\mathrm{P}}$ からなるとし, 界面 張力も同様と考えると，（8）式は

$$
\begin{aligned}
\cos \theta= & -1+2\left(\gamma_{\mathrm{S}}^{\mathrm{D}} \gamma_{\mathrm{L}}^{\mathrm{D}}\right)^{1 / 2} \cdot \gamma_{\mathrm{L}}^{-1}+2\left(\gamma_{\mathrm{S}}^{\mathrm{P}} \gamma_{\mathrm{L}}^{\mathrm{P}}\right)^{1 / 2} \\
& \cdot \gamma_{\mathrm{L}}^{-1}-\pi_{\mathrm{e}} \cdot \gamma_{\mathrm{L}}^{-1}
\end{aligned}
$$

となる。ここで $\gamma_{\mathrm{S}}^{\mathrm{D}} と \gamma_{\mathrm{L}}^{\mathrm{D}}$ はそれぞれ固体及び液体の表 面張力の分散成分を， $\gamma_{\mathrm{S}}^{\mathrm{P}}$ と $\gamma_{\mathrm{L}}^{\mathrm{P}}$ は極性成分を表す。した がって， $\gamma_{\mathrm{L}}^{\mathrm{D}}$ と $\gamma_{\mathrm{L}}^{\mathrm{P}}$ が既知の液体を作業液体として固体の 接触角を測定し，更に $\pi_{\mathrm{e}}$ が分れば，（9）式によって固 体の表面張力を分散力成分亡非分散力成分に分けて求め ることができる。

\section{3. $3 \mathrm{As}_{2} \mathrm{~S}_{3}, \mathrm{As}_{2} \mathrm{~S}_{5}, \mathrm{As}_{2} \mathrm{Se}_{3}$ の $\gamma_{\mathrm{s}}$ 試算}

2 種類以上の液体の接触角から（9）式によって固体 の表面張力を求めるには，作業液体の $\gamma_{\mathrm{L}}^{\mathrm{D}}$ と $\gamma_{\mathrm{L}}^{\mathrm{P}}$ の値の ほかに $\pi_{\mathrm{e}}$ の值も関係する。ここで選んだ液体の表面張 力としては, 表 2 に引用した值を用いた。 $\pi_{\mathrm{e}}$ につては, $\theta>0^{\circ}$ の場合はこれを無視できるとする近似を用いた。 したがって（9）式を

$$
\cos \theta=-1+2\left(\gamma_{\mathrm{S}}^{\mathrm{D}} \gamma_{\mathrm{L}}^{\mathrm{D}}\right)^{1 / 2} \cdot \gamma_{\mathrm{L}}^{-1}+2\left(\gamma_{\mathrm{S}}^{\mathrm{P}} \gamma_{\mathrm{L}}^{\mathrm{P}}\right)^{1 / 2} \cdot \gamma_{\mathrm{L}}^{-1}
$$

\begin{tabular}{|c|c|c|c|}
\hline \multirow[t]{2}{*}{ Liquid } & Surface & free & energy/mJ m-2 \\
\hline & $Y_{L}$ & $r_{L}^{D}$ & $Y_{L}^{P}$ \\
\hline Water & 72.0 & 23.2 & 48.8 \\
\hline Formamide & 58.3 & 32.3 & 26.0 \\
\hline Ethylene glycol & 48.9 & 33.4 & 15.5 \\
\hline 1,3-Butanedio1 & 39.1 & 32.5 & 6.6 \\
\hline 1-Nitropropane ${ }^{2}$ ) & 30.2 & 21.0 & 9.2 \\
\hline
\end{tabular}

とする（10）式に基づいて $\gamma_{\mathrm{s}}$ の試算を行った結果を以 下に述べる。

\section{3. $3.1 \quad \mathrm{As}_{2} \mathrm{~S}_{3}$}

$\gamma_{\mathrm{s}}$ が分散力成分 $\gamma_{\mathrm{s}}^{\mathrm{D}}$ だけを含むときは $(10)$ 式は

$$
\cos \theta=-1+2\left(\gamma_{\mathrm{S}}^{\mathrm{D}} \gamma_{\mathrm{L}}^{\mathrm{D}}\right)^{1 / 2} \cdot \gamma_{\mathrm{L}}^{-1}
$$

Table 2. Surface free energies of the wetting liquids ${ }^{1}$ 


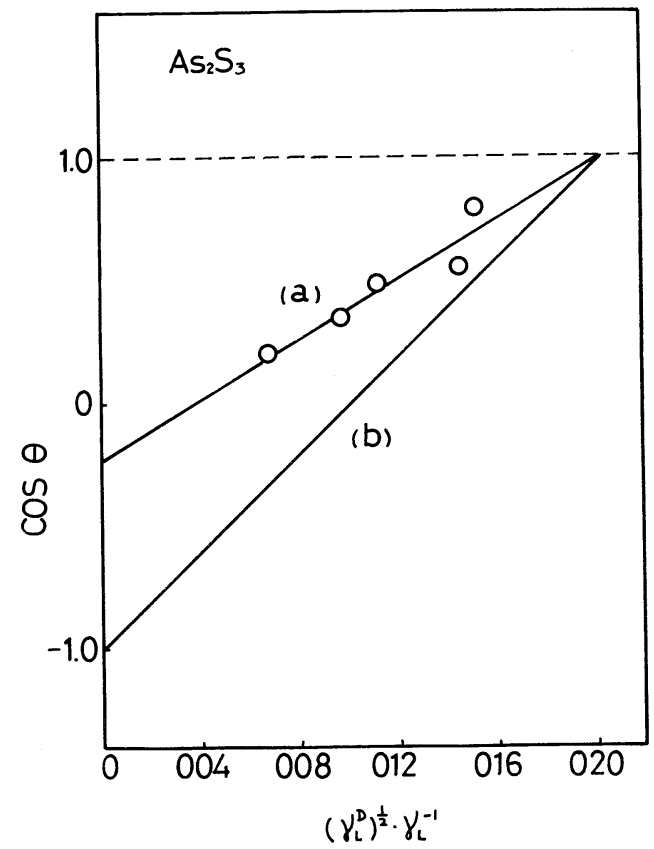

Fig. 3. Plot of $\cos \theta$ vs. $\left(\gamma_{\mathrm{L}}^{\mathrm{D}}\right)^{1 / 2} \cdot \gamma_{\mathrm{L}}^{-1}$ for $\mathrm{As}_{2} \mathrm{~S}_{3}$. (a) and (b): in the text

上なるので, $\cos \theta を\left(\gamma_{\mathrm{L}}^{\mathrm{D}}\right)^{1 / 2} \cdot \gamma_{\mathrm{L}}^{-1}$ に対してプロットす ると, $2\left(\gamma_{\mathrm{S}}^{\mathrm{D}}\right)^{1 / 2}$ のこう配をもつ直線が得られ，このこう 配から $\gamma_{\mathrm{S}}^{\mathrm{D}}$ を求めることができる. $\mathrm{As}_{2} \mathrm{~S}_{3}$ についてプロッ 卜する上, 図3の(a) で示す直線が得られる。接触角が

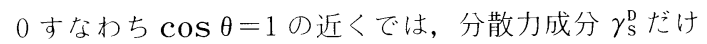
が相互作用に寄与しているとするBirdi ら ${ }^{101}$ の近似に従 えば, 直線図 3 (a) が $\cos \theta=1$ をよぎる点, つまり図 3 の破線亡の交点では, 分散力による寄与だけが㗢いて いると考えることができる.

一方, (11) 式で $\left(\gamma_{\mathrm{L}}^{\mathrm{D}}\right)^{1 / 2} \cdot \gamma_{\mathrm{L}}^{-1}=0$ の上き $\cos \theta$ の切 片は - 1である。したがって, 図 3 の直線 (b) は, 分 散力成分 $\gamma_{\mathrm{s}}^{\mathrm{D}}$ だけが働くときの相関性を表すことにな る。言い換えれば，固体の表面張力が分散力による寄与 だけである場合 $\left(\gamma_{\mathrm{S}}=\gamma_{\mathrm{S}}^{\mathrm{D}}+\gamma_{\mathrm{S}}^{\mathrm{P}}\right.$ で $\left.\gamma_{\mathrm{S}}^{\mathrm{P}}=0\right)$ は, $\cos \theta$ と( $\left.\gamma_{\mathrm{L}}^{\mathrm{D}}\right)$ ${ }^{1 / 2} \cdot \gamma_{\mathrm{L}}^{-1}$ のプロットは図 $3(\mathrm{~b})$ の上にのらなければいけ ない. 図 3 のように $\theta$ の実測值によるプロット $(\mathrm{a})$ が $(\mathrm{b})$ 亡一致しないのは, $\gamma_{\mathrm{S}}^{\mathrm{P}} \neq 0$ の寄与が加わるためであると 考えることができる。したがって，(10) 式から（11） 式を引いた

$$
\left(\cos \theta_{\mathrm{DP}}-\cos \theta_{\mathrm{D}}\right)=2\left(\gamma_{\mathrm{S}}^{\mathrm{P}} \gamma_{\mathrm{L}}^{\mathrm{P}}\right)^{1 / 2} \cdot \gamma_{\mathrm{L}}^{-1}
$$

によって極性成分 $\gamma_{\mathrm{S}}^{\mathrm{P}}$ を求めることができる. (12) 式 で $\theta_{\mathrm{DP}}$ は分散力成分と極性成分の両方が相互作用に寄与 している場合を表し， $\theta_{\mathrm{D}}$ は分散力成分だけが寄与して いる場合を表す。

図 3 ( a) は,

$$
\theta_{\mathrm{DP}}=6.02\left(\gamma_{\mathrm{L}}^{\mathrm{D}}\right)^{1 / 2} \cdot \gamma_{\mathrm{L}}^{-1}-0.23
$$

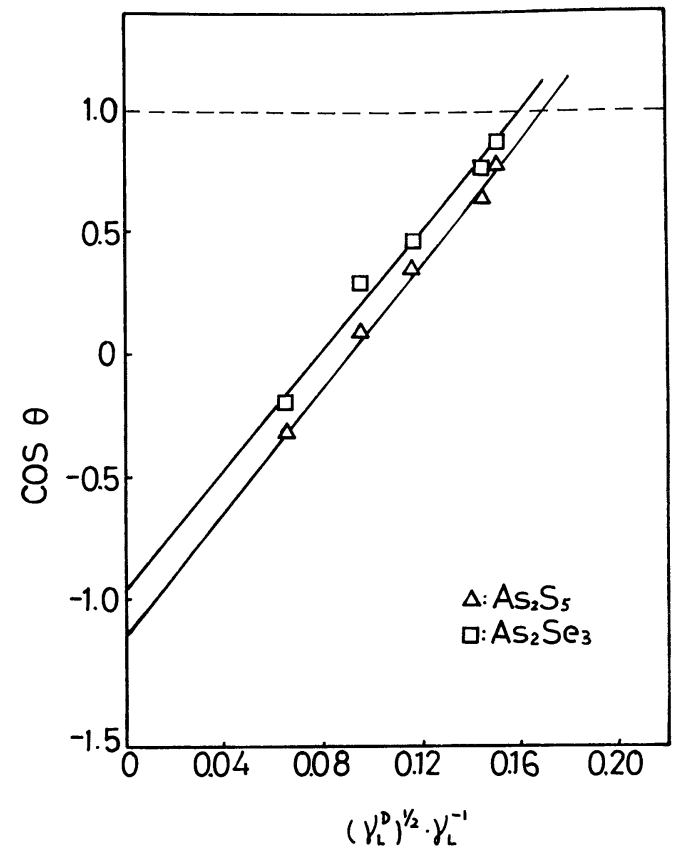

Fig. 4. Plot of $\cos \theta$ vs. $\left(\gamma_{\mathrm{L}}^{\mathrm{D}}\right)^{1 / 2} \cdot \gamma_{\mathrm{L}}^{-1}$ for $\mathrm{As}_{2} \mathrm{~S}_{5}$ and $\mathrm{As}_{2} \mathrm{Se}_{3}$

で表されるので, $\cos \theta=1$ のとき $\left(\gamma_{\mathrm{L}}^{\mathrm{D}}\right)^{1 / 2} \cdot \gamma_{\mathrm{L}}^{-1}$ は 0.2 となる. $\left(\cos \theta,\left(\gamma_{\mathrm{L}}^{\mathrm{D}}\right)^{1 / 2} \cdot \gamma_{\mathrm{L}}^{-1}\right)$ が $(1,0.2)$ と $(-1,0)$ を結ぶ直線図 3 (b) のこう配は 10 である。すなわち 2 $\left(\gamma_{\mathrm{S}}^{\mathrm{D}}\right)^{1 / 2}=10$ であるから, $\gamma_{\mathrm{S}}^{\mathrm{D}}=25 \mathrm{~mJ} \cdot \mathrm{m}^{-2}$ が得られる.

一方，ここで用いた作業液体について（12）式で求め た $\gamma_{\mathrm{s}}^{\mathrm{P}} / \mathrm{mJ} \cdot \mathrm{m}^{-2}$ は, それぞれ 7.8 (水), 4.6 (ホルムア ミド), 3.8(エチレングリコール $), 1.0(1,3-$ ブタンジオ一 ル) 及び 2.1 (1-ニトロプロパン) であった. 液体によっ てかなり異なるが，いずれにしても $\gamma_{\mathrm{S}}^{\mathrm{D}}$ に比較してかな り小さいことは推定できる. $\gamma_{\mathrm{s}}=\gamma_{\mathrm{s}}^{\mathrm{D}}+\gamma_{\mathrm{S}}^{\mathrm{P}}$ から, 接触角 から求めた $\mathrm{As}_{2} \mathrm{~S}_{3}$ の $\gamma_{\mathrm{s}}$ は $26 \sim 33 / \mathrm{mJ} \cdot \mathrm{m}^{-2}$ 程度というこ とになる。

\subsection{2 $\mathrm{As}_{2} \mathrm{~S}_{5}$ 及び $\mathrm{As}_{2} \mathrm{Se}_{3}$}

$\mathrm{As}_{2} \mathrm{~S}_{3}$ と同様に $\cos \theta$ を $\left(\gamma_{\mathrm{L}}^{\mathrm{P}}\right)^{1 / 2} \cdot \gamma_{\mathrm{L}}^{-1}$ に対してプロッ 卜すると，図 4 に示す直線となり，それぞれは

$$
\begin{aligned}
& \mathrm{As}_{2} \mathrm{~S}_{5}: \cos \theta=12.61\left(\gamma_{\mathrm{L}}^{\mathrm{D}}\right)^{1 / 2} \cdot \gamma_{\mathrm{L}}^{-1}-1.15 \\
& \mathrm{As}_{2} \mathrm{Se}_{3}: \cos \theta=12.01\left(\gamma_{\mathrm{L}}^{\mathrm{D}}\right)^{1 / 2} \cdot \gamma_{\mathrm{L}}^{-1}-0.96
\end{aligned}
$$

にフィットする. $\left(\gamma_{\mathrm{L}}^{\mathrm{D}}\right)^{1 / 2} \cdot \gamma_{\mathrm{L}}^{-1}=0$ での $\cos \theta$ の切片は ビちらも -1 に近い. 3.2 節で述べた近似に従えば, 切 片をー1 とすると $\mathrm{As}_{2} \mathrm{~S}_{5}$ と $\mathrm{As}_{2} \mathrm{Se}_{3}$ の表面張力は分散力 成分だけを含むことになる.

(14), (15) 式の直線が $\cos \theta=1$ を切る点は, $\left(\gamma_{\mathrm{L}}^{\mathrm{D}}\right)^{1 / 2} \cdot \gamma_{\mathrm{L}}=0.17$ 及び 0.16 である.これらの点と $(-1$, 0)を結ぶ直線のこう配が $2\left(\gamma_{\mathrm{S}}^{\mathrm{D}}\right)^{1 / 2}$ に等しいとして求め た $\gamma_{\mathrm{s}}^{\mathrm{D}}$ の值は, それぞれ $34.4 \mathrm{~mJ} \cdot \mathrm{m}^{-2}\left(\mathrm{As}_{2} \mathrm{~S}_{5}\right)$ 及び $37.5 \mathrm{~mJ} \cdot \mathrm{m}^{-2}\left(\mathrm{As}_{2} \mathrm{Se}_{3}\right)$ であった. 


\section{4. 結論}

水にぬ机にい性質等から，低エネルギ一表面をもつ と推測される硫化ヒ素及びセレン化ヒ素粉体について, 水及び 4 種の有機液体の接触角を測定した。界面張力に 幾何平均近似を用いて,これら固体の表面張力を求めた 結果, いずれも $30 \mathrm{~mJ} \cdot \mathrm{m}^{-2}$ 前後で, 低表面エネルギー の有機高分子に近い值であった.

$\mathrm{As}_{2} \mathrm{~S}_{5}$ と $\mathrm{As}_{2} \mathrm{Se}_{3}$ は水の接触角が $90^{\circ}$ より大きく，ま た本研究で用いた近似では分散力成分のみを含むとみな すことができる．一方， $\mathrm{As}_{2} \mathrm{~S}_{3}$ の表面張力には極性成分 が含まれるが，分散力成分に比較してかなり小さいと推 定される.

以上の結果は，粉体力ラム浸透法によって測定される 接触角の精度, 表面圧無視の妥当性等の吟味を加えたう えで，今後更に検討すべき余地を残している.
謝辞 本研究の一部は文部省科学研究費補助金(課題番 号：58208025）によったことを付記し，謝意を表する.

\section{文献}

1) M. Hattori and T. Ogasawara, Thermochim. Acta, 63, 51-58 (1983).

2) J. Li and M. Hattori, ibid., 88, 267-72 (1985).

3) M. Hattori T. Ogasawara, and J. Li. J. Colloid Interf. Sci., in press.

4) P. M. Heertjes and N. F. Kossen, Powder Techn., 1, 33-42 (1967).

5) M. L. Studebaker and C. W. Snow, J. Phys. Chem. , 59, 973-76 (1955).

6) D. T. Hansford, D. J.W. Grant and J.M. Newton, J. Chem. Soc. Farad. Trans, I, 76, 2417-31 (1980).

7) F. M. Fowkes, Ind. Eng. Chem., 5640-52 (1964).

8) G. Zografi and S. Tam., J. Pharm. Soc., 65, 1146-49 (1976).

9) J. Panzer, J. Colloid Interf. Sci., 44, 142-61 (1973).

10) K. S. Birdi and J. Jeppesen, Colloid Polym. Sci., 256, 261-65 (1978).

11) H. J. Busscher and J. Arends, J. Colloid Interf. Sci, 81, 75-79 (1981). 